\title{
Maternal and neonatal outcome in placenta praevia and adherent placenta: A retrospective study in a tertiary care center
}

\author{
Chaitra Shivananjaiah, Preeti Malapure, Esha Shanbhag, Satish Kumar, Satiah, \\ Renuka Ramaiah
}

Correspondence: Dr Chaitra Shivananjaiah, Senior Resident, Department of Obstetrics and Gynaecology, ESIC Medical College and Hospital, India; Email - chaittra.shiv@gmail.com

Distributed under Creative Commons Attribution-Share Alike 4.0 International.

\begin{abstract}
Objective: The study was conducted to see the maternal and neonatal outcomes of the women with placenta praevia. Methods: All women with the diagnosis of placenta praevia admitted in the hospital were included in the study. The maternal and fetal outcomes were recorded from January 2012 to August 2017, over a period of 5 years. Results: A total of 63 patients were included in the study, after radiological confirmation. The period of gestation for the first presentation was predominantly in 28 weeks of gestation, for central placenta praevia. The mean blood loss intraoperative was $3000 \mathrm{ml}$, ranging to as much as $5500 \mathrm{ml}$ in central placenta praevia and more so in posterior than anterior placenta. The need of additional procedure like uterine artery ligation was needed in $26(41.2 \%)$, internal iliac artery ligation 8 (12.6\%), B lynch in $12(19.04 \%)$ and peripartum hysterectomy was performed in $3(4.7 \%)$. The mean requirement of blood transfusion was $500 \mathrm{ml}$ of packed cell. The need of ICU care was in $5(7.9 \%)$ and serious morbidity was seen in $3(4.7 \%)$. Maternal mortality was not seen in any case. Fetal outcomes were studied by recording the fetal weight, Apgar and need of NICU care which was for 23 (36.5\%). Conclusion: The need for early diagnosis and multispecialty approach to a patient is greatly associated with reducing the blood loss, lesser need of additional procedure and lower maternal and fetal mortality and morbidity.
\end{abstract}

Keywords: Placenta praevia, accreta, antepartum hemorrhage, maternal complication.

Placenta praevia means the placenta located in the lower uterine segment which is less than $2.5 \mathrm{cms}$ from the cervical os ${ }^{1}$. This condition is complicating about 0.3 to $0.8 \%$ of all pregnancy ${ }^{2-5}$. The risk factors for developing placenta praevia are previously scarred uterus, grand multiparty, maternal age of more than 35 years, recurrent abortion and intrauterine curettage ${ }^{6-9}$.

Maternal morbidity in the form of abnormal placentation, increased risk of section and additional procedure, need for blood transfusion and ICU care and fetal morbidity in the form of preterm, low birth weight, low Apgar and need for NICU care makes it a must for care in a higher center and with available advanced resources ${ }^{10-13}$. The most frequent management in the form of section which is on the rise in today's era more so increases the risk of placenta praevia in the next

Received: 12 th August 2017. Accepted: 7 th December 2017.

Shivananjaiah C, Malapure P, Shanbhag E, Kumar S, Satiah, Ramaiah R. Maternal and neonatal outcome in placenta praevia and adherent placenta: A retrospective study in a tertiary care center. The New Indian Journal of OBGYN. $2018 ; 4(2): 150-53$. 
pregnancy and also the placenta accreta ${ }^{14,15}$. In a woman with placenta praevia in the first pregnancy the risk of developing placenta praevia is $1-3 \%$ in contrast to a multigravida where the risk is $30-51 \%$ higher ${ }^{16}$. In a study conducted by Zhang et al the risk of placenta accreta was $3 \%, 40 \%, 61 \%$ and $67 \%$ in the first, second, third and fourth generation respectively ${ }^{17}$.

The higher incidence of placenta praevia in the third stage of labor in the most common indication for peripartum hysterectomy. The maternal mortality is as high as $7 \%$ and causes for which is attributed to hypovolemic shock leading to DIC, massive transfusion, infection, thrombophlebitis, urological complication $^{18,19}$.

The exact pathology of the placenta praevia is not known to us, in the year 2010 Healy and team reported the higher incidence of placenta praevia in endometriosis patients following conception by artificial reproductive technique ${ }^{20}$.

Placenta praevia is a very serious obstetric complication and needs a team effort for management of the same. The emotional stress the patient goes through and the professional pressure the obstetrician carries makes the environment tensed and to reduce the incidence of placenta praevia and avoid the dreaded consequence, the better.

The aim of this study was to study the presentation of the women with placenta praevia and the associated maternal and neonatal mortality and morbidity.

Materials and Methods

This retrospective cross sectional study performed in the Department of Obstetrics and Gynecology at ESIC medical college, Bangalore, between January 2012 to August 2017. Women with documented radiological confirmation of placenta praevia were included in the study. The data of the women were collected from the records, including the age, parity, gestation age, presenting complains, grade of placenta praevia, previous significant history of uterine manipulation, mode of delivery, intraoperative and post operative complications, post operative period and complications. The fetal information in the form of the period of gestation, birth weight, need for NICU care. The data thus collected were analyzed by SPSS software version 18.

\section{Results}

Over 5 years from January 2012 to August 2017, total of 63 patients were enrolled in the study. The location of the placenta which was diagnosed by the ultrasound was

Table 1: Maternal characteristics

\begin{tabular}{lll}
\hline Variables & & Number (\%) \\
\hline Age in years & $20-25$ & $27(42.9 \%)$ \\
& $26-30$ & $27(42.9 \%)$ \\
Gravida/Parity & $31-35$ & $9(14.2 \%)$ \\
& $\mathrm{G}_{1}$ & $18(28.5 \%)$ \\
& $\mathrm{G}_{2}$ & $23(36.5 \%)$ \\
& $\mathrm{G}_{3}$ & $13(20.7 \%)$ \\
Period of gestation & $\geq \mathrm{G}_{4}$ & $9(14.3 \%)$ \\
& $<37$ wks & $14(22.2 \%)$ \\
Previous h/o CS, miscarriage and D \& E & $49(77.8 \%)$ \\
& $>37(23.8 \%)$ \\
\hline
\end{tabular}

confirmed in the intraoperative period, 16(25.3\%) were complete placenta praevia and $8(12.69 \%)$ was partial placenta praevia, $13(20.63 \%)$ cases were marginal and low lying was in $26(41.2 \%)$.

Table 2: Maternal outcome

\begin{tabular}{lll}
\hline Maternal features & & Number (\%) \\
\hline $\begin{array}{l}\text { Mode of } \\
\text { delivery }\end{array}$ & Normal & - \\
& Operative vaginal & - \\
Additional & LSCS & $63(100 \%)$ \\
operative procedures & Stepwise devascularization & $34(53.9 \%)$ \\
& Compressive suture & $12(19.4 \%)$ \\
Blood transfusions & Peripartum hysterectomy & $3(4.7 \%)$ \\
& PCV & $23(36.5 \%)$ \\
& FFP & $19(30.15 \%)$ \\
& Platelets & $12(19.04 \%)$ \\
\hline
\end{tabular}

The mean age of the women was 28 (ranging from 21 to 35 years), the mean parity ranging from Primigravidae to Gravida 5. Previous sections were noted in 15 (23.8\%) of the women, the indications being low lying placenta and fetal distress (Table 1). The period of termination of the pregnancy was $14(22.2 \%)$ before 37 weeks and 49 (77.7\%) after 37 weeks. The early termination was noted in type 2 and type 4 placenta praevia.

The mean blood loss intraoperative was $3000 \mathrm{ml}$, ranging to as much as $5500 \mathrm{ml}$ in central placenta praevia and more so in posterior than anterior placenta. The need 
of additional procedure like uterine artery ligation was needed in $26(41.2 \%)$, internal iliac artery ligation 8 (12.6\%), B lynch in $12(19.04 \%)$ and peripartum

Table 3: Fetal outcome

\begin{tabular}{lll}
\hline Fetal variables & & Number $(\%)$ \\
\hline Preterm & & $10(15.8 \%)$ \\
Birth weight in Kgs & $<1.5$ & $3(4.7 \%)$ \\
& $1.5-2.5$ & $22(34.9 \%)$ \\
& $>2.5$ & $38(60.31 \%)$ \\
NICU admission & & $23(36.5 \%)$ \\
APGAR Score & 1 minute $<7$ & $16(25.3 \%)$ \\
& 5 minute $<7$ & $7(11.2 \%)$ \\
\hline
\end{tabular}

hysterectomy was performed in $3(4.7 \%)$ (Table 2). The mean requirement of blood transfusion was $500 \mathrm{ml}$ of packed cell. The need of ICU care was in $5(7.9 \%)$ and serious morbidity was seen in $3(4.7 \%)$. Maternal mortality was not seen in any case. Fetal outcomes were studied by recording the fetal weight, Apgar and need of NICU care (Table 3).

\section{Discussion}

In this study, the morbidity was significantly higher, which is well proven in the literature ${ }^{10-13}$. Placenta praevia is one of the most deadly complication in obstetrics, due to its strong adverse effect on the both the mother and the child. Higher age of the patient and increased parity has been found to be the most important risk factors to develop placenta praevia. Twenty seven $(42.8 \%)$ of the women were between the age group $26-$ 30 years and $9(14.2 \%)$ were more than 30 years of age, which was much lower than the study conducted by Sarojini et al, Ojha $\mathrm{N}$ et al and $\mathrm{Wu} \mathrm{S}$ et al ${ }^{13,20,21,23}$. Seventy five percent of the women in the study conducted by Sarojini with placenta praevia were multigravida which was similar to present study where multigravida were $45(71.4 \%)^{21}$.

Thirty three $(52.3 \%)$ patients were managed by Macafee protocol, in whom women were advice bed rest, regular blood investigations, vigilant watch for vaginal bleed, frequent fetal surveillance by regular USG, steroid prophylaxis for preterm and blood being cross matched and kept ready, this method of medical management of placenta praevia was found to improve both the maternal and perinatal outcome ${ }^{21}$.
In this study the previous history of abortion, need for curettage and previous section was noted in $22(34.9 \%)$ and $15(23.8 \%)$ respectively. In a retrospective cohort study of 399 women conducted by Urganchi et al. placenta praevia in the present pregnancy was noted in 4.4 per 1000 births, compared to 8.7 per 1000 birth for women with cesarean section in the first pregnancy ${ }^{22}$. In the study by Ojha et al, previous history of abortions had a significant increase in the prevalence of placenta praevia i.e three times in comparison to the women with no history of dilation and curettage ${ }^{23}$.

In this study all the 63 women underwent section, a trial was given in $12(19.04 \%)$ patients but due to fetal distress and bleed per vagina were taken for an emergency section and the remaining 51 (80.9\%) women were posted for elective section due to major degree of placenta praevia, in comparison to a study conducted by Sarojini $(85.8 \%)^{20}$ and Anand et al $(84.3 \%)^{24}$.

Post partum hemorrhage was noted in $34(53.9 \%)$ of the women, of whom 3 (4.7\%) needed peripartum hysterectomy. Additional surgical procedures in the form of step wise devascularization $34 \quad(53.9 \%)$ and compressive suture - B - lynch in 12 (19.04\%), in comparison to a study conducted by Sarojini et al were cervico isthmic suture was needed in $4.7 \%$, B-lynch in $2.8 \%$ and uterine artery ligation in $1.9 \%$ of the women. ${ }^{20}$

The neonatal morbidity was noted in $23(36.5 \%)$ of the newborns, all of them needed NICU care, 10 (15.8\%) of them were preterm and needed surfactant to support the respiratory system. The Apgar at one minute was also found to be low in 23 (36.9\%) of the newborn and needed additional emergency care. In comparison to a study conducted by Sarojini were preterm was documented in $30.2 \%^{20}$.

\section{Conclusion}

Regular antenatal check for early detection and exclusion of placenta previa is mandatory, to prevent the maternal mortality and morbidity. More vigilant watch in elderly women, women with high parity and with history of previous section, myomectomy and dilation and curettage. Scan, Doppler and MRI to rule out adherent placenta should be done in cases of women diagnosed with placenta previa, in whom there is positive history of surgical procedure performed on the uterus.

Conflict of interest: None. Disclaimer: Nil. 


\section{References}

1)Leveno KJ, Alexander JM, Bloom SL, et al. Placenta previa. In: Williams' Manual of Pregnancy Complications. 23rd ed. New York : McGraw-Hill; 2013.

2)Tuzovic L, Djelmis J, Ilijic M. Obstetric Risk Factors Associated with Placenta Previa Development: Case-Control Study. Croatian Medical Journal. 2003; 44: 728-33.

3)Dola CP, Garite TJ, Dowling DD, Friend D, Ahdoot D, Asrat T. Placenta Previa: Does Its Type Affect Pregnancy Outcome? American Journal of Perinatology. 2003; 20: 35360.

4)Gorodeski IG, Bahari CM. The Effect of Placenta Previa Localization upon Maternal and Fetal-Neonatal Outcome. Journal of Perinatal Medicine. 1987; 15: 169-77.

5)Love CD, Wallace EM. Pregnancies Complicated by Placenta Praevia: What Is Appropriate Management? Br J Obstet Gynaecol. 1996 Sep; 103(9): 864-7.

6)Singh PM, Rodrigues C, Gupta AN. Placenta Previa and Previous Cesarean Section. Acta Obstetriciaet Gynecologica Scandinavica. 1981; 60: 367-68.

7)To WW, Leung WC. Placenta Previa and Previous Cesarean Section. International Journal of Gynecology and Obstetrics. 1995; 51: 25-31.

8)Sheiner E, ShohamVardi I, Hallak M, Hershkowitz R, Katz M, Mazor M. Placenta Previa: Obstetric Risk Factors and Pregnancy Outcome. Journal of Maternal-Fetal and Neonatal Medicine. 2001; 10: 414-19.

9)Demissie K, Breckenridge MB, Joseph L, Rhoads GG. Placenta Previa: Preponderance of Male Sex at Birth. American Journal of Epidemiology. 1999; 149: 824-30.

10)McShane P, Heyl P. Maternal and perinatal morbidity resulting from placenta previa. Obstet Gynecol. 1985; 65: 176-82.

11)Frederiksen FC, Glassenberg R, Stika CS. Placenta previa: a 22-year analysis. Am J Obstet Gynecol. 1999; 180: 1432-37.

12)Faiz AS, Anath CV. Etiology and risk factors for placenta previa: an overview and meta-analysis of observational studies. J Matern Fetal Neonatal Med. 2003; 13: 175-90.

13)Wu S, Kocherginsky M, Hibbard J. Abnormal placentation: twenty-year analysis. Am J Obstet Gynecol. 2005; 192: 1458-61.

14)Plascencia JL, Ochoa FI, Zuniga MA, Karchmer S. Placenta Praevia/Accreta and Previous Cesarean Section. Experience of Five Years at the Mexico National Institute of
Perinatalogy. Ginecología y Obstetricia de México. 1995; 63: 337-40.

15)Lavary SP. Placenta Previa. Clinical Obstetrics and Gynecology. 1990; 33: 414.

16)Miller DA, Chollet JA, Goodwin TM. Clinical Risk Factors for Placenta Previa - Placenta Accreta. American Journal of Obstetrics \& Gynecology. 1997; 177: 210-14.

17)Zhang J, Savitz DA. Maternal Age and Placenta Previa: A Population-Based, Case-Control Study. American Journal of Obstetrics \& Gynecology. 1993; 168: 641-45.

18)O'Brien JM, Barton JR, Donaldson ES. The Management of Placenta Percreta: Conservative and Operative Strategies. American Journal of Obstetrics \& Gynecology. 1996; 175: 1632-38.

19)Healy DL, Breheny S, Halliday J, et al. Prevalence and risk factors for obstetric haemorrhage in 6730 singleton births after assisted reproductive technology in Victoria Australia. Human Reproduction. 2010; 25(1): 265-74.

20)Sarojini, Malini KV, Radhika. Clinical study of placenta previa and its effect on maternal health and fetal outcome. Int J Reprod Contracept Obstet Gynecol. 2016; 5: 3496-9.

21)Bhatt AD, Meena A, Desai MR. Maternal and perinatal outcome in cases of placenta previa. Int J Sci Res. 2014; 3(1): 299-301.

22)Urganchi GI, Cromwell AC, Edozien LC, Smith GCS, Onwere C, Mahmood TA, et al. Risk of placenta previa in second birth after birth cesarean section: a population-based study and meta-analysis. BMC Pregnancy Childbirth. 2011; 11: 95.

23)Ojha N. Obstetric factors and pregnancy outcome in placenta previa. J Institute Med. 2012; 34: 38-41.

24)Ananth CV, Demissie K, Smulian JC, Vintzileos AM. Relationship among placenta previa, fetal growth restriction and preterm delivery: a population based study. Obstet Gynecol. 2001; 98(2): 299-306.

\footnotetext{
Chaitra Shivananjaiah ${ }^{1}$, Preeti Malapure ${ }^{2}$, Esha Shanbhag ${ }^{3}$, Satish Kumar ${ }^{4}$, Satiah ${ }^{5}$, Renuka Ramaiah $^{6}$

${ }^{1}$ Senior Resident, ${ }^{2}$ Junior Resident, ${ }^{3}$ Senior Resident, ${ }^{4}$ Junior Resident, ${ }^{5}$ Junior Resident, ${ }^{6}$ Professor \& HOD, Department of Obstetrics and Gynaecology, ESIC Medical College and Hospital, Bangalore, Karnataka, India.
} 